\title{
Possibility of NiCuZn Ferrites Composition for Stress Sensor Applications
}

\author{
M. Penchal Reddy, ${ }^{1}$ W. Madhuri, ${ }^{2}$ M. Venkata Ramana, ${ }^{3}$ I. G. Kim, ${ }^{1}$ D. S. Yoo, \\ N. Ramamanohar Reddy, ${ }^{4}$ K. V. Siva Kumar, ${ }^{5}$ D. V. Subbaiah, ${ }^{5}$ and R. Ramakrishna Reddy \\ ${ }^{1}$ Department of Physics, Changwon National University, Changwon 641773, Republic of Korea \\ ${ }^{2}$ School of Advanced Sciences, VIT University, Vellore 632014, India \\ ${ }^{3}$ School of Materials Science and Engineering, Harbin Institute of Technology, Shenzhen 518055, China \\ ${ }^{4}$ Department of Materials Science and Nanotechnology, Yogi Vemana University, Kadapa 516227, India \\ ${ }^{5}$ Department of Physics, Sri Krishnadevaraya University, Anantapur 515055, India \\ Correspondence should be addressed to I. G. Kim; igkim@changwon.ac.kr
}

Received 5 November 2012; Accepted 10 December 2012

Academic Editor: Zhenxing Yue

Copyright ( $) 2013$ M. Penchal Reddy et al. This is an open access article distributed under the Creative Commons Attribution License, which permits unrestricted use, distribution, and reproduction in any medium, provided the original work is properly cited.

\begin{abstract}
NiCuZn ferrite with composition of $\left(\mathrm{Ni}_{0.42+x} \mathrm{Cu}_{0.10} \mathrm{Zn}_{0.60} \mathrm{Fe}_{1.76-2 x} \mathrm{O}_{3.76-2 x}\right)$ (where $x=0.00,0.02,0.04,0.06,0.08$, and 0.10) was prepared by the conventional ceramic double sintering technique. The formation of single phase was confirmed by X-ray diffraction. The microstructural features were also studied by electronic microscopy and are reported. Initial permeability measurements on these samples were carried out in the temperature range of 30 to $300^{\circ} \mathrm{C}$. The effect of external applied stress on the open magnetic circuit type coil with these ferrite cores was studied by applying uniaxial compressive stress parallel to the magnetizing direction and the change in the inductance was measured. The variation of inductance $(\Delta L / L) \%$ increases up to certain applied compressive stress and there after it decreases, showing different stress sensitivities for different compositions of ferrites studied in the present work. The variation of ratio of inductance $(\Delta L / L) \%$ with external applied compressive stress was examined. These results show that the $\mathrm{Ni}_{0.42} \mathrm{Cu}_{0.10} \mathrm{Zn}_{0.60} \mathrm{Fe}_{1.76} \mathrm{O}_{3.76}$ and $\mathrm{Ni}_{0.44} \mathrm{Cu}_{0.10} \mathrm{Zn}_{0.60} \mathrm{Fe}_{1.72} \mathrm{O}_{3.72}$ samples are found to be suitable for inductive stress sensor applications.
\end{abstract}

\section{Introduction}

It is well known that the effect of stress is very important in the magnetization process of ferrites [1]. The magnetic properties of ferrites such as permeability, coercivity, and hysteresis loop change with the application of stress $[2,3]$. The effect of external applied stress can be observed in ferrites as a change of inductance $(\Delta L / L) \%$ when compressive stresses are applied. These variations of permeability with applied stress in these samples can be attributed to the magnetostrictive contributions of varied amounts of nickel and iron compositions. For small compressive stresses, the stress raises the initial permeability with negative magnetostriction and for large tensile stresses the permeability decreases [3]. The magnetoelastic properties of ferrites are interesting subjects for investigations to determine the possibilities of their use in the construction of measuring sensors $[4,5]$. Over the last decade, manganese substituted cobalt ferrites have been the dominant ferrite materials for stress sensor applications due to their large magnetomechanical effect and high sensitivity to stress [6-11]. Magnetic sensors play a significant role in physical measurements used in all kinds of applications $[12,13]$. The most often used magnetic phenomena in today's magnetic sensor technology are the magnetoresistance [14, $15]$, the magnetoimpedance $[16,17]$, the magnetostriction $[18,19]$, the electromagnetic induction [20], and the Hall effect [21]. There also exist other effects usable in sensing applications, both macroscopic and microscopic [22]. Due to superior mechanical and magnetic properties in ferrites they 
seem to be suitable for construction of force and stress sensors $[23,24]$.

This led to systematic investigation of studies on the stress sensitivity of series of NiCuZn [25], MgCuZn, and $\mathrm{NiMgCuZn} \mathrm{[26]} \mathrm{ferrites.} \mathrm{Incidentally} \mathrm{it} \mathrm{has} \mathrm{been} \mathrm{noticed}$ from these studies that certain $\mathrm{NiCuZn}$ ferrite compositions can be used for stress sensor applications. In view of this the details of synthesis of those NiCuZn ferrite compositions suitable for stress sensor applications and their stress dependence studies are reported in this paper.

\section{Experimental Procedure}

A series of six nonstoichiometric compositions of $\mathrm{NiCuZn}$ ferrite with compositions shown in Table 1 have been prepared by the conventional double sintering method using analytical grade $\mathrm{NiO}, \mathrm{CuO}, \mathrm{ZnO}$, and $\mathrm{Fe}_{2} \mathrm{O}_{3}$ in their respective proportions. These oxides were weighed and intimately mixed in stoichimetric proportions. These constituents were ball milled (RETSCH PM - 200, Germany) in agate bowls with agate balls in acetone medium for $20 \mathrm{~h}$. The slurry was dried and the dried powders were loosely packed in the form of cakes. These cakes were presintered in closed alumina crucibles at $800^{\circ} \mathrm{C}$ for $2 \mathrm{~h}$. The presintered cakes removed from the furnace were crushed and ball milled in an acetone medium in agate bowls with agate balls for another 24 hours to obtain fine particle size. These slurries after drying were sieved to obtain uniform particle size.

The presintered green powders were mixed with $2 \%$ polyvinyl alcohol as a binder and were compacted in the form of disks of diameter $10 \mathrm{~mm}$ and $2 \mathrm{~mm}$ height, toroids of $12 \mathrm{~mm}$ outer diameter (OD), $8 \mathrm{~mm}$ inner diameter (ID) and $4 \mathrm{~mm}$ height and cylinders of diameter $10 \mathrm{~mm}$ and length nearly $20 \mathrm{~mm}$ at $200 \mathrm{MPa}$ with a suitable die. The compacted bodies were conventionally sintered in a programmable furnace (V.B. Ceramic Consultants, Chennai, India) at a temperature of $1250^{\circ} \mathrm{C}$ for 2 hours and were cooled to room temperature at $80^{\circ} \mathrm{C} / \mathrm{hr}$. The sintering schedule includes half an hour dwelling time at $110^{\circ} \mathrm{C}$ to remove moisture from the samples and one-hour binding burning time at $600^{\circ} \mathrm{C}$. Proper care was taken to avoid zinc evaporation by providing $\mathrm{ZnFe}_{2} \mathrm{O}_{4}$. The density of the sintered specimens was measured by Archimedes's method. All the samples were structurally characterized using Philip high resolution X-ray diffraction system (PM 1730, Germany) with $\mathrm{CuK}_{\alpha}$ radiation. Microstructures of sintered samples were investigated using JOEL (JSM Model 6360, Japan) scanning electron microscope. The initial permeability $\left(\mu_{i}\right)$ of these ferrite toroids was evaluated using the standard formulae from the inductance measurements carried out at a frequency of $10 \mathrm{kHz}$ using computer controlled impedance analyzer (Hioki Model 3532-50 LCR Hi-Tester, Japan). These measurements were carried out in the temperature range 30 to $300^{\circ} \mathrm{C}$. In order to study the effect of external stress, uniaxial compressive stress parallel to the magnetizing direction was applied to the cylindrical shaped ferrite cores using uniaxial press system. The stress magnitudes were varied from 0 to $10 \mathrm{MPa}$.
TABle 1: Chemical composition of the NiCuZn ferrites.

\begin{tabular}{lccccc}
\hline S. No. & Sample & $\mathrm{NiO}$ & $\mathrm{CuO}$ & $\mathrm{ZnO}$ & $\mathrm{Fe}_{2} \mathrm{O}_{3}$ \\
\hline 1 & $\mathrm{a}$ & 21 & 5 & 30 & 44 \\
2 & $\mathrm{~b}$ & 22 & 5 & 30 & 43 \\
3 & $\mathrm{c}$ & 23 & 5 & 30 & 42 \\
4 & $\mathrm{~d}$ & 24 & 5 & 30 & 41 \\
5 & $\mathrm{e}$ & 25 & 5 & 30 & 40 \\
6 & $\mathrm{f}$ & 26 & 5 & 30 & 39 \\
\hline
\end{tabular}

a: $\mathrm{Ni}_{0.42} \mathrm{Cu}_{0.10} \mathrm{Zn}_{0.60} \mathrm{Fe}_{1.76} \mathrm{O}_{3.76}$, b: $\mathrm{Ni}_{0.44} \mathrm{Cu}_{0.10} \mathrm{Zn}_{0.60} \mathrm{Fe}_{1.72} \mathrm{O}_{3.72}$, c: $\mathrm{Ni}_{0.46} \mathrm{Cu}_{0.10} \mathrm{Zn}_{0.60} \mathrm{Fe}_{1.68} \mathrm{O}_{3.68}, \mathrm{~d}: \mathrm{Ni}_{0.48} \mathrm{Cu}_{0.10} \mathrm{Zn}_{0.60} \mathrm{Fe}_{1.64} \mathrm{O}_{3.64}$,

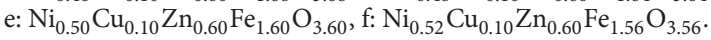

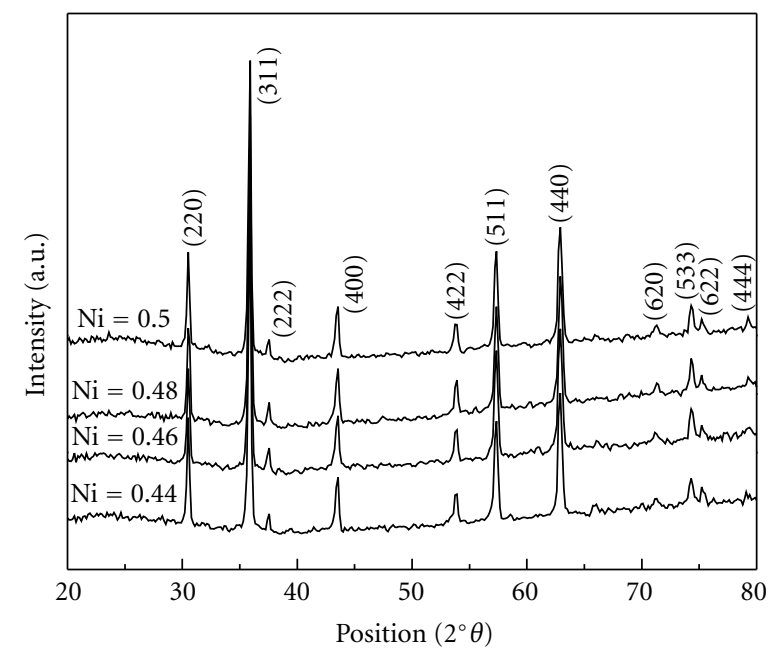

FIGURE 1: Typical X-ray diffractograms of $x=0.2,0.4,0.6$, and 0.8 .

The change in inductance was measured using the abovementioned LCR Hi-Tester by employing 100-120 turns coil on each cylinder. The initial permeability was calculated using the relation

$$
L=0.0046 N^{2} \mu_{i} h \log _{10}\left(\frac{D_{o}}{D_{i}}\right),
$$

where $L$ is the series inductance; $N$ is the number of turns of winding; $h$ is the height of the toroid in inches; $D_{o}$ is the outer diameter of toroid; and $D_{i}$ is the inner diameter of toroid, respectively.

\section{Results and Discussion}

Figure 1 represents the typical X-ray diffractograms of nonstoichiometric NiCuZn ferrite samples, respectively. The Xray diffraction analysis of the ferrite samples shows the formation of single phase spinel structure. The X-ray lines show considerable broadening, indicating the fine particle nature of the ferrite powder.

The variation of the lattice parameter " $a$ " as a function of nickel ion content is depicted in Figure 2. It is noticed that the lattice parameter increases with the nickel ion content in the lattice. This variation can be explained on the basis of an ionic size difference of the component ions. It may be 


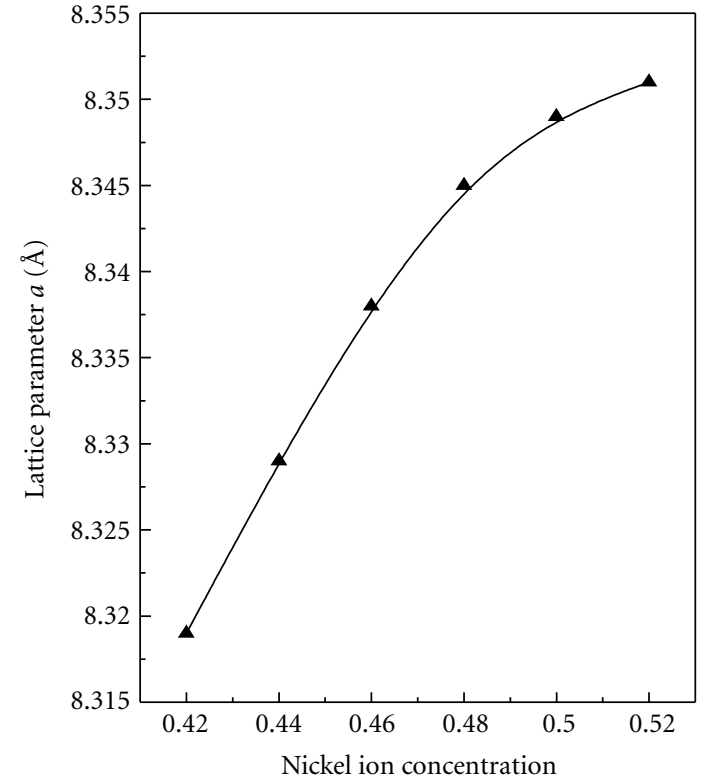

FIGURE 2: Lattice constant $(a)$ as a function of nickel ion concentration of the NiCuZn system.

pointed out here that the ionic radii of $\mathrm{Ni}^{2+}, \mathrm{Cu}^{2+}$, and $\mathrm{Zn}^{2+}$ are almost same with the experimental error that is, $0.72 \AA$, $0.74 \AA$, and $0.74 \AA$, respectively [27]. However the lattice parameter is found to increase systematically with increase in nickel content.

The SEM photographs of the sintered samples were recorded to understand the microstructure of the NiCuZn ferrites. Scanning electron microscopy (SEM) of powder sintered at $1250^{\circ} \mathrm{C} / 2 \mathrm{~h}$ shows an increase in particle size increasing the nickel concentration [28]. Figures 3(a) and $3(\mathrm{~b})$ show the microstructures of fracture surfaces of the sample b (Ni 0.44) and sample d (Ni 0.48) (Table 1). It is well known that the initial permeability characteristics depend not only on chemical composition but also on the microstructure of the sintered body. Desired magnetic properties of ferrite can be achieved by the control of microstructures [29]. Small and uniform grain size is favourable to obtain low power loss, but large grain size is favourable to get high permeability [30].

Figure 4 shows the variation of the initial permeability $\left(\mu_{i}\right)$ versus the nickel content for samples at room temperature $\left(27^{\circ} \mathrm{C}\right)$. It can be noticed from the figure that the initial permeability shows a maximum at 0.48 nickel content in these nonstoichiometric NiCuZn ferrospinels. This may be attributed to the fact that the magnetocrystalline anisotropy constant $\left(K_{1}\right)$ becoming zero at this composition of nickel $[31,32]$.

The initial permeability $\left(\mu_{i}\right)$ as the function of temperature (at constant frequency, $10 \mathrm{kHz}$ ) from room temperature to Curie point was also studied. The temperature dependence of magnetic anisotropy can be inferred from the temperature dependence of initial permeability as shown in Figure 5. It can be noted from Figure 5 that as the temperature increases the initial permeability $\left(\mu_{i}\right)$ remains constant up to a certain temperature and increases to a peak value and

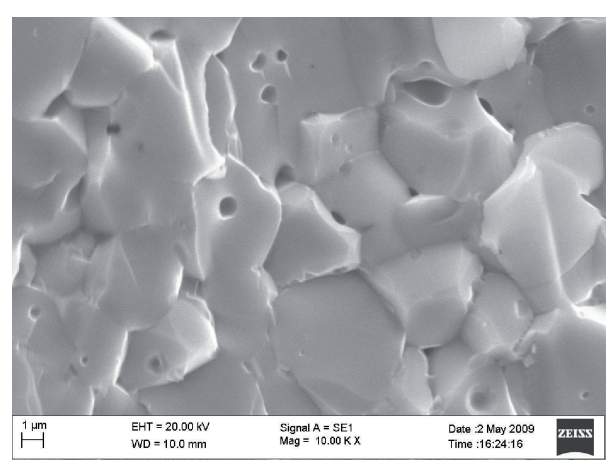

(a)

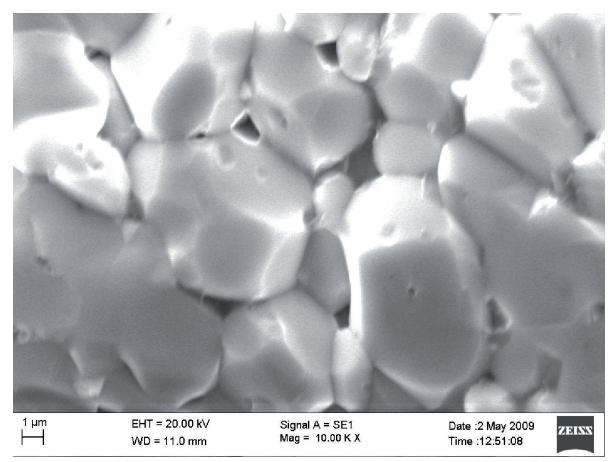

(b)

FIGURE 3: SEM photographs of sintered $\left(\mathrm{Ni}_{0.42+x} \mathrm{Cu}_{0.10} \mathrm{Zn}_{0.60} \mathrm{Fe}_{1.76-2 x}\right.$ $\mathrm{O}_{3.76-2 x}$ ) ferrites (a) $x=0.2$ and (b) 0.6.

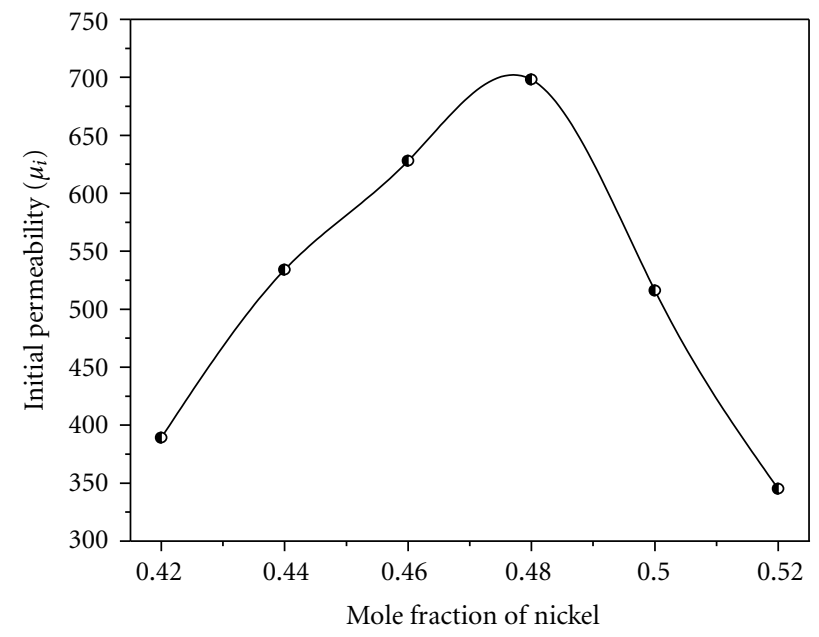

FIGURE 4: Variation of initial permeability with mole fraction of nickel at room temperature.

then abruptly falls to a minimum value. The temperature at which this abrupt fall takes place is the magnetic Curie transition temperature $T_{c}$. The magnetic initial permeability for the material is expected to strongly depend on the microstructure, as the initial permeability represents the mobility of magnetic domain wall in response to the small applied field [33]. It is proved by Figures 3(a) and 3(b) that 


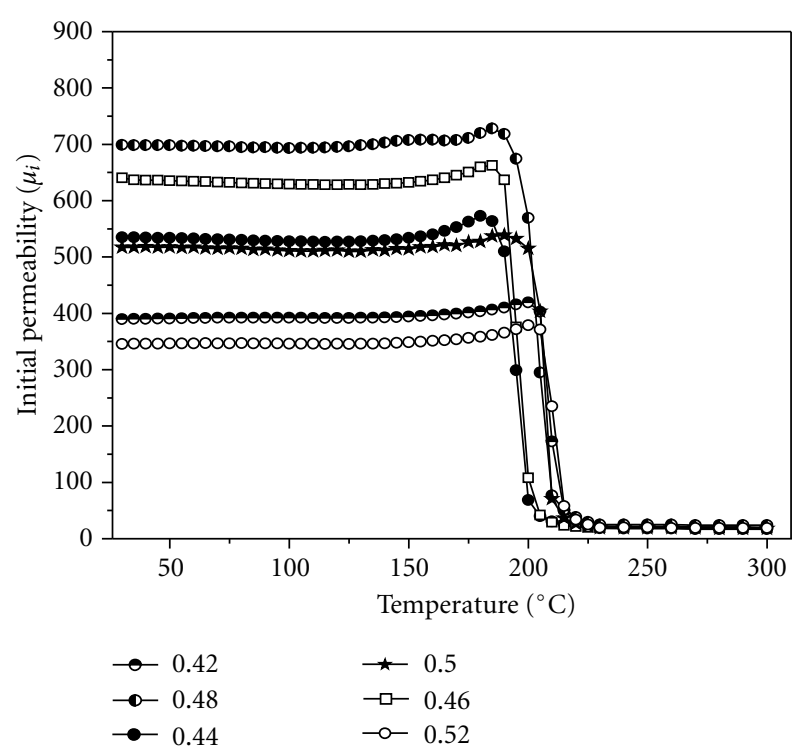

FIgURE 5: Temperature dependence of the initial permeability of $\left(\mathrm{Ni}_{0.42+x} \mathrm{Cu}_{0.10} \mathrm{Zn}_{0.60} \mathrm{Fe}_{1.76-2 x} \mathrm{O}_{3.76-2 x}\right)$ ferrites sintered at $1250^{\circ} \mathrm{C} / 2 \mathrm{~h}$.

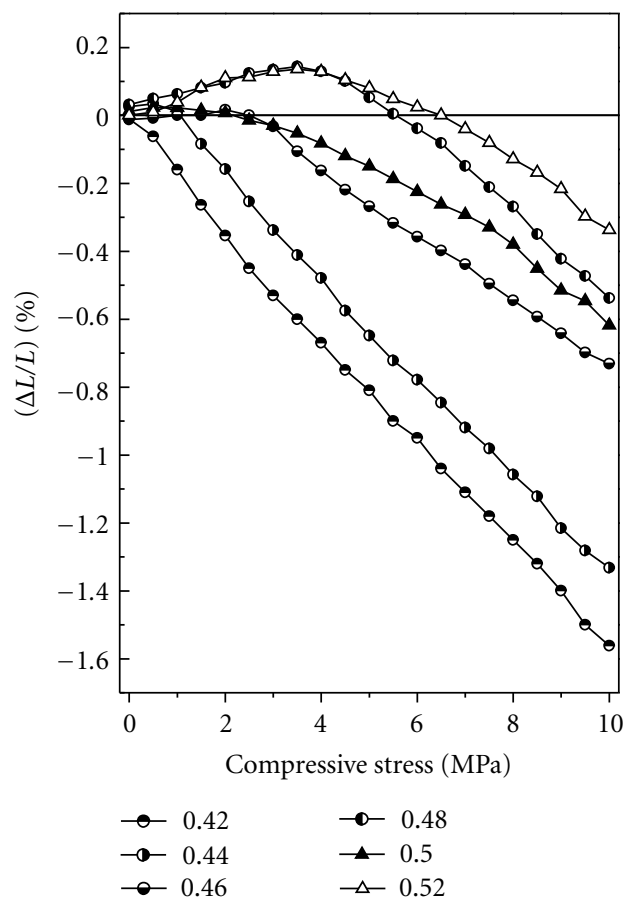

FIGURE 6: Variation of ratio of inductance change $(\Delta L / L) \%$ as a function of applied compressive stress in non-stoichiometric $\mathrm{NiCuZn}$ ferrite series.

the magnetic permeability of the large-grain samples is larger than the fine-grain ones.

The initial permeability is an important magnetic property to study the quality of soft ferrites. Generally, the initial permeability $\left(\mu_{i}\right)$ depends on two factors [34] namely, (1) contribution from spin rotation and (2) contribution from domain wall motion. But the contribution from spin rotation is smaller than domain wall motion [35]. The permeability due to domain wall motion is given by [36]

$$
\left(\mu_{i}-1\right)=\frac{3 \pi M_{s}^{2} D}{4 \gamma},
$$

where $M_{s}$ is saturation magnetization, $D$ is mean grain size, and $\gamma$ is magnetic domain wall energy, which is proportional to magnetocrystalline anisotropy constant $K_{1}[37,38]$.

Thus

$$
\left(\mu_{i}\right)_{w}=\frac{M_{s}^{2} D}{K_{1}},
$$

where $\left(\mu_{i}\right)_{w}$ is the initial permeability of domain wall motion.

The magnitudes of initial permeability $\left(\mu_{i}\right)$ increased with increasing content of nickel up to 0.48 after decreasing with increasing nickel content and interestingly the Curie transition temperature remained fairly constant around $200^{\circ} \mathrm{C}$. The figure reveals that there is a flat temperature response of $\left(\mu_{i}\right)$ in all these samples. The Curie transition temperature and permeability behaviour as a function of nickel content in these ferrites were published in earlier communication [25].

The variation of ratio of inductance change $(\Delta L / L) \%$ as a function of applied compressive stress is shown in Figure 6. From an examination of Figure 6 it is clear that in samples a and $\mathrm{b}$ the $(\Delta L / L) \%$ values decrease with increasing external stress. In the case of samples $\mathrm{d}$ and $\mathrm{f}$, there is an increase of $(\Delta L / L) \%$ up to certain applied stress and thereafter it decreases. At higher concentrations of nickel the $(\Delta L / L) \%$ increases up to a certain stress and decreases with further raise in external compressive stress showing a peak value. Exactly, similar behaviour was noticed by Kanada et al., [39] in $\mathrm{NiMgCuZn}$ ferrites at $4 \mathrm{MPa}$. For example these peak values are $3.5 \mathrm{MPa}, 2 \mathrm{MPa}$, and $3.5 \mathrm{MPa}$ for nickel contents $0.48,0.50$, and 0.52 , respectively. In the present work, we have studied variation of inductance at low concentration of nickel. This type of behaviour dependency of $(\Delta L / L) \%$ on stress can be utilized for the development of a sensor for detection of stress variations.

\section{Conclusions}

The initial permeability measurements were carried out in the temperature range $30-300^{\circ} \mathrm{C}$ in NiCuZn ferrites. In the present study it has been noticed that there is a linear decrease of $(\Delta L / L) \%$ with increasing external applied stress in ferrite compositions with nickel 0.42 , and 0.44 concentration. The compositions $\mathrm{Ni}_{0.42} \mathrm{Cu}_{0.10} \mathrm{Zn}_{0.60} \mathrm{Fe}_{1.76} \mathrm{O}_{3.76}$, and $\mathrm{Ni}_{0.44} \mathrm{Cu}_{0.10} \mathrm{Zn}_{0.60} \mathrm{Fe}_{1.72} \mathrm{O}_{3.72}$ showed best magnetic properties among the five compositions and would be prominent materials for inductive stress sensor applications.

\section{References}

[1] G. Mian and T. Yamaguchi, "Stress effect on the magnetization process in $\mathrm{Ni}-\mathrm{Cu}-\mathrm{Zn}$ ferrite in a weak field," Journal of Magnetism and Magnetic Materials, vol. 68, pp. 351-357, 1987.

[2] A. Biehkowski, "Ferrite," in Proceedings of the ICF3, Center for Academic Publishers, Tokyo, Japan, 1981. 
[3] J. Smit and H. P. Wijn, Ferrites, Philips Technical Library, Eindhoven, The Netherlands, 1959.

[4] A. Bierikowski, Acta IMEKO, p. 591, 1979.

[5] A. Bienkowski and J. Kulikowski, Prace ITR, vol. 97, p. 10, 1984.

[6] S. S. Shinde and K. M. Jadhav, "Bulk magnetic properties of cobalt ferrite doped with Si4+ ions," Journal of Materials Science Letters, vol. 17, no. 10, pp. 849-851, 1998.

[7] J. A. Paulsen, C. C. H. Lo, J. E. Snyder, A. P. Ring, L. L. Jones, and D. C. Jiles, "Study of the curie temperature of cobalt ferrite based composites for stress sensor applications," IEEE Transactions on Magnetics, vol. 39, no. 5, pp. 3316-3318, 2003.

[8] J. A. Paulsen, A. P. Ring, C. C. H. Lo, J. E. Snyder, and D. C. Jiles, "Manganese-substituted cobalt ferrite magnetostrictive materials for magnetic stress sensor applications," Journal of Applied Physics, vol. 97, no. 4, Article ID 044502, 3 pages, 2005.

[9] O. Caltun, H. Chiriac, N. Lupu, I. Dumitru, and B. P. Rao, "High magnetostrictive doped cobalt ferrite," Journal of Optoelectronics and Advanced Materials, vol. 9, no. 4, pp. 1158-1160, 2007.

[10] O. F. Caltun, G. S. N. Rao, K. H. Rao et al., "High magnetostrictive cobalt ferrite for sensor applications," Sensor Letters, vol. 5, no. 1, pp. 45-47, 2007.

[11] O. Caltun, I. Dumitru, M. Feder, N. Lupu, and H. Chiriac, "Substituted cobalt ferrites for sensors applications," Journal of Magnetism and Magnetic Materials, vol. 320, no. 20, pp. e869-e873, 2008.

[12] G. Brumfiel, "Magnetic effect sends physicists into a spin," Nature, vol. 426, no. 6963, p. 110, 2003.

[13] E. Hristoforou, "Magnetic effects in physical sensor design and development," Journal of Optoelectronics and Advanced Materials, vol. 4, no. 2, pp. 245-260, 2002.

[14] I. Bakonyi, B. L. Peter, V. Weihnacht, J. Toth, L. F. Kiss, and C. M. Schneider, "Giant magnetoresistance in electrodeposited multilayer films. The influence of superparamagnetic regions," Journal of Optoelectronics and Advanced Materials, vol. 7, no. 2, pp. 589-598, 2005.

[15] V. Georgescu and M. Daub, "Magnetism and magnetoresistance in electrodeposited $\left(\mathrm{L}_{0}\right)$ CoPt superlattices," Journal of Optoelectronics and Advanced Materials, vol. 7, no. 2, pp. 853-858, 2005.

[16] J. M. Barandiarán, M. L. Fdez-Gubieda, J. Gutiérrez, I. Orúe, A. G. Arribas, and G. V. Kurlyandskaya, "Magnetic films of technical interest prepared by pulsed laser deposition," Journal of Optoelectronics and Advanced Materials, vol. 6, no. 2, pp. 565-574, 2004.

[17] L. V. Panina, D. P. Makhnovskiy, and K. Mohri, "Magnetoimpedance in amorphous wires and multifunctional applications: from sensors to tunable artificial microwave materials," Journal of Magnetism and Magnetic Materials, vol. 272, part 2, pp. 1452-1459, 2004.

[18] H. C. Jiang, W. L. Zhang, W. X. Zhang, S. Q. Yang, and H. W. Zhang, "Influences of sputtering angles and annealing temperatures on the magnetic and magnet ostrictive performances of TbFe films," Journal of Materials Science \& Technology, vol. 21, no. 3, p. 315, 2005.

[19] P. Ciureanu, G. Rudkowska, L. Clime, A. Sklyuyev, and A. Yelon, "Anisotropy optimization of giant magnetoimpedance sensors," Journal of Optoelectronics and Advanced Materials, vol. 6, no. 3, pp. 905-910, 2004.

[20] D. De Cos, A. García-Arribas, and J. M. Barandiarán, "Simplified electronic interfaces for sensors based on inductance changes," Sensors and Actuators A, vol. 112, no. 2-3, pp. 302-307, 2004.
[21] G. Boero, I. Utke, T. Bret et al., "Submicrometer Hall devices fabricated by focused electron-beam-induced deposition," Applied Physics Letters, vol. 86, no. 4, Article ID 042503, 3 pages, 2005.

[22] H. Chiriac, M. Tibu, V. Dobrea, and I. Murgulescu, "Thin magnetic amorphous wires for GMI sensor," Journal of Optoelectronics and Advanced Materials, vol. 6, no. 2, pp. 647-650, 2004.

[23] A. Bienkowski and R. Szewczky, "new possibility of utilizing amorphous ring cores as stress sensor," Physica Status Solidi A, vol. 189, no. 3, pp. 787-790, 2002.

[24] A. Bienkowski and J. Kulikowski, "The magneto-elastic Villari effect in ferrites," Journal of Magnetism and Magnetic Materials, vol. 19, no. 1-3, pp. 120-122, 1980.

[25] N. R. Reddy, M. V. Ramana, G. Rajitha, E. Rajagopal, K. V. Sivakumar, and V. R. K. Murthy, "Stress sensitivity of inductance in NiCuZn ferrites," Journal of Magnetism and Magnetic Materials, vol. 292, pp. 159-163, 2005.

[26] N. Varalaxmi, N. R. Reddy, M. V. Ramana et al., "Stress sensitivity of inductance in NiMgCuZn ferrites and development of a stress insensitive ferrite composition for microinductors," Journal of Materials Science: Materials in Electronics, vol. 19, pp. 399-405, 2008.

[27] N. Varalaxmi and D. Ph, [Ph.D. thesis], Sri Krishnadevaraya University, Anantapur, India, 2007.

[28] U. R. Lima, M. C. Nasar, R. S. Nasar, M. C. Rezende, J. H. Araujo, and J. F. Olivera, "Synthesis of NiCuZn ferrite nanoparticles and microwave absorption characterization," Materials Science and Engineering B, vol. 151, no. 3, pp. 238-242, 2008.

[29] S. I. Pyun and J. T. Baek, "Microstructural dependence of permeability and permeability spectra in Ni-Zn ferrites," American Ceramic Society Bulletin, vol. 64, no. 4, pp. 602-605, 1985.

[30] T. Y. Byun, S. C. Byeon, K. S. Hong, and C. K. Kim, "Factors affecting initial permeability of Co-substituted $\mathrm{Ni}-\mathrm{Zn}-\mathrm{Cu}$ ferrites," IEEE Transactions on Magnetics, vol. 35, no. 5, pp. 3445-3447, 1999.

[31] U. B. Deshmukh, S. M. Kabbur, N. D. Chaudhari, S. R. Sawant, and S. Suryavansi, in Proceedings of the National Conference on Electronic Materials Devices and Systems (NCEMDS '99), p. 231, Gulbarga, India, 1999.

[32] J. Loaec, "Thermal hysteresis of the initial permeability of soft ferrites at transition temperatures," Journal of Physics D, vol. 26, no. 6, p. 963.

[33] C. Y. Tsay, K. S. Liu, and I. N. Lin, "Microwave sintering of $\left(\mathrm{Bi}_{0.75} \mathrm{Ca}_{1.2} \mathrm{Y}_{1.05}\right)\left(\mathrm{V}_{0.6} \mathrm{Fe}_{4.4}\right) \mathrm{O}_{12}$ microwave magnetic materials," Journal of the European Ceramic Society, vol. 24, no. 6, pp. 1057-1061, 2004.

[34] A. Globus, P. Duplex, and M. Guyot, "Determination of initial magnetization curve from crystallites size and effective anisotropy field," IEEE Transactions on Magnetics, vol. 7, no. 3, p. $617,1971$.

[35] O. F. Caltun, L. Spinub, A. L. Stancua, L. D. Thungb, and W. Zhou, "Study of the microstructure and of the permeability spectra of Ni-Zn-Cu ferrites," Journal of Magnetism and Magnetic Materials, vol. 242-245, pp. 160-162, 2002.

[36] G. Baca, R. Valenzuela, M. A. Escobar, and L. F. Magaña, "Temperature dependence of the critical magnetic field in polycrystalline ferrites," Journal of Applied Physics, vol. 57, no. 8, pp. 4183-4185, 1985.

[37] T. Y. Byun, S. C. Bycon, and K. S. Hong, "Factors affecting initial permeability of Co-substituted Ni-Zn-Cu ferrites," IEEE Transactions on Magnetics, vol. 35, no. 5, pp. 3445-3447, 1999. 
[38] M. Guyot and A. Globus, "wall displacement and bulging in magnetization mechanisms of the hysteresis loop," Physica Status Solidi B, vol. 52, no. 2, pp. 427-431, 1972.

[39] I. Kanada, T. Murse, and T. Nomura, "Effect of chemical composition and microstructure on stress sensitivity of ferrite," Journal of the Japan Society of Powder and Powder Metallurgy, vol. 48, pp. 135-139, 2001. 

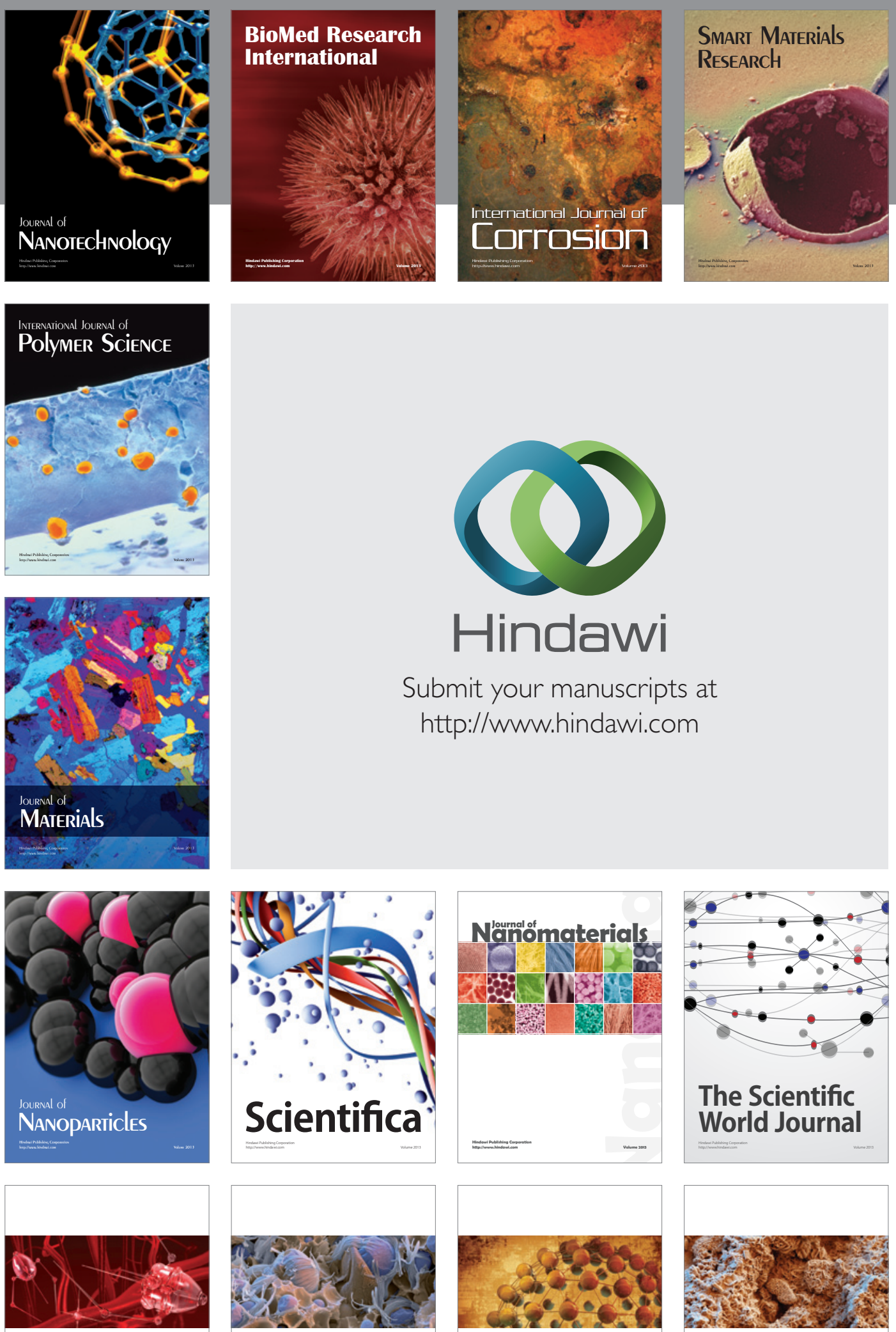

ISRN

Nanotechnology
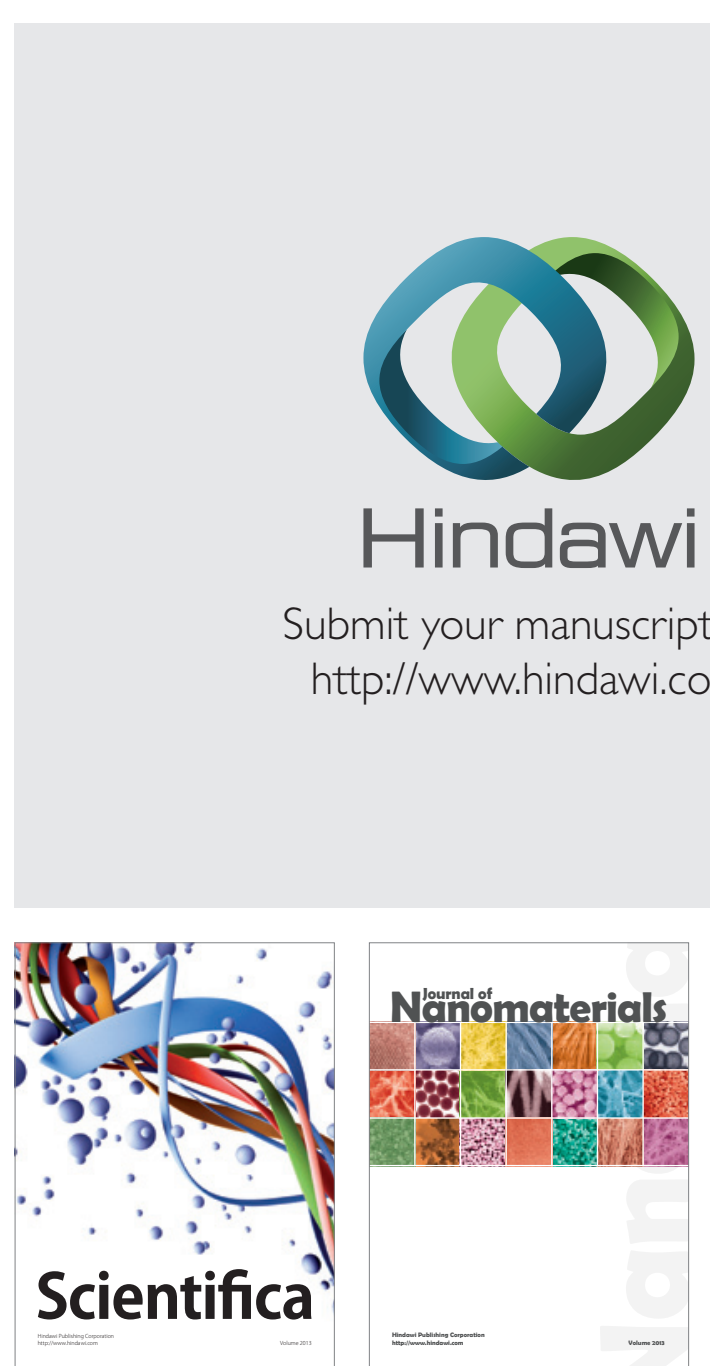

Submit your manuscripts at http://www.hindawi.com
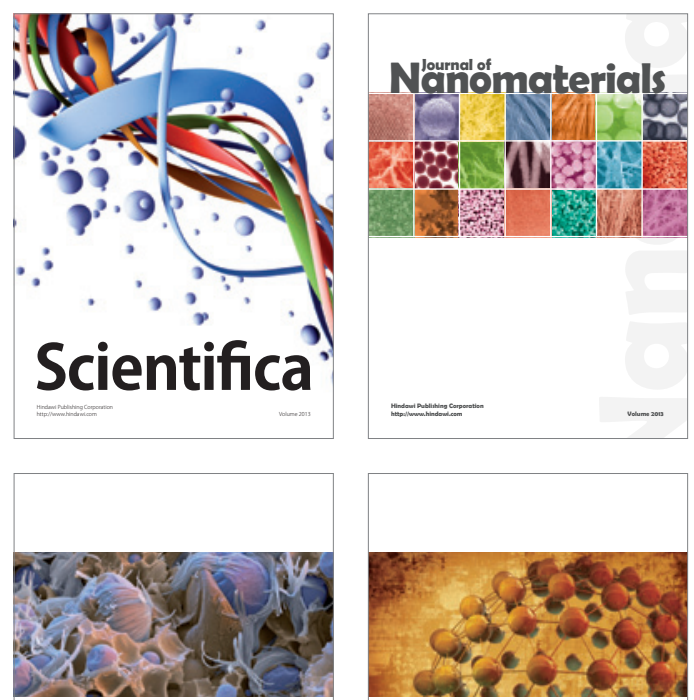

ISRN

Polymer Science

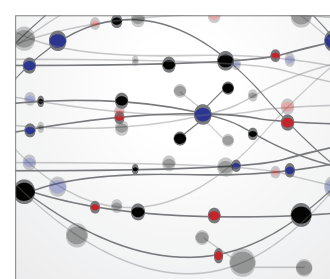

The Scientific World Journal

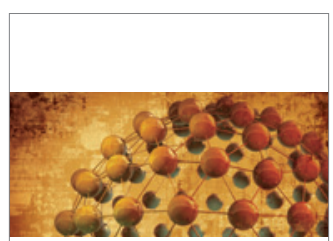

ISRN

Materials Science

\section{World Jounal}

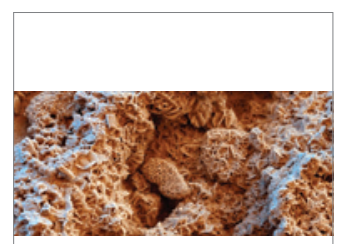

ISRN

Corrosion
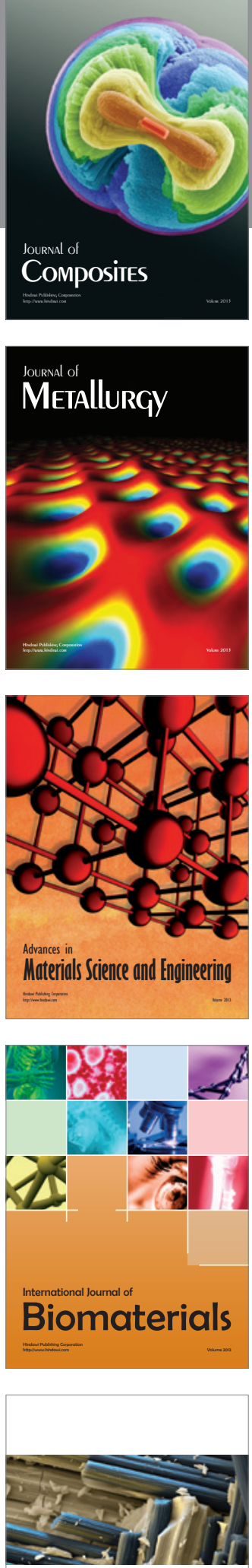

ISRN

Ceramics 